\title{
Mecanoquímica: Moer, Esmagar... Reacção!
}

\author{
Vasco D.B. Bonifácio \\ CQFM e IN, Instituto Superior Técnico, Universidade de Lisboa \\ vasco.bonifacio@tecnico.ulisboa.pt
}

Mechanochemistry in action: grind and go! - In the last few years mechanochemistry has emerged as an alternative green methodology in organic synthesis. Simple, solventless, low cost and highly efficient, the ancient process of grinding turned out as a smart tool for sustainable chemistry. From small molecules to complex systems, mechanochemistry rocks.

\begin{abstract}
A mecanoquímica ressurgiu nos últimos anos como uma alternativa muito interessante para a síntese orgânica sustentável, ou mais amiga do ambiente. A técnica de moagem é ancestral e tem sido usada em diversos processos, contudo as reações químicas em estado sólido, sob o ponto de vista da química sustentável, são uma estratégia muito inteligente. A simplicidade do método, aliada a baixos custos e elevada eficiência, sem recurso ao uso de solvente de reacção (contornando também problemas de solubilidade), são altamente atractivas. Da síntese de pequenas moléculas até aos sistemas mais complexos a mecanoquímica vai certamente agitar os químicos!
\end{abstract}

De médico e louco todos temos um pouco, diz o provérbio. Eu acrescentaria que o químico e o cozinheiro se conhecem pelo cheiro! Pelos melhores e pelos piores exemplos. Sim, porque a química não faz só perfumes e na cozinha também há distrações. Se entra bispo na panela ou enxofre na molécula, o melhor é abrir a janela. Odores à parte, o almofariz e o pilão (mortarium e pistillum em latim) estão quase sempre presentes nestas profissões. Em madeira, pedra, porcelana vidro, bronze ou ágata, só precisam de mão hábil e muita paciência. Embora sejam objectos muito antigos, com registos que datam de 35000 a.C. [1], foram associados ao longos dos séculos a mezinhas e outros imaginários (Figura 1).

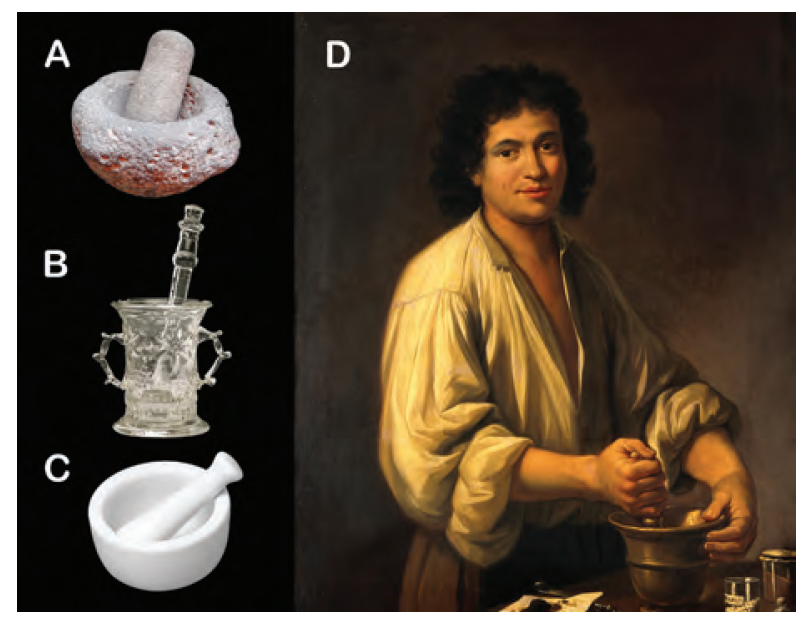

Figura 1 - A arte de moer, usando almofariz e pilão em diversos materiais: A) pedra, período Neolítico, Museu de Cultura Yarmukian em Israel. B) vidro veneziano, séc. XVII-XVIII. C) porcelana, séc. XX. D) bronze, “An apothecary (a man using pestle and mortar)”, óleo sobre tela séc. XIV, Welcome Library, Londres.

Na química estão muito associados aos laboratórios de farmácia, sendo o principal objectivo desta técnica reduzir o tamanho da partículas do fármaco de modo a facilitar a sua absorção após administração oral ou a sua biodisponibilidade usando administração nasal.
À parte de uma acção puramente mecânica existe de facto uma química muito interessante no simples acto de moer. Desde a preparação de novos co-cristais [2] até às reações mais complexas, podemos fazer quase tudo, basta juntar os reagentes certos. A procura de processos químicos mais sustentáveis foi uma alavanca no ressurgimento e crescente interesse pela mecanoquímica. Numa "química verde" a ideia de não usarmos solventes é de facto ideal, e não é só numa perspectiva ambiental. De facto um dos maiores problemas com que nós químicos nos deparamos no dia-a-dia é a solubilidade. Uma dor de cabeça! "Não é solúvel em diclorometano, nem em éter, nem acetona ou metanol... vou tentar dimetilsulfóxido". Por vezes nem a escolha mais radical nos salva, e quando o faz traz outros problemas... então e se... não usarmos solvente? $[3,4]$.

Embora o cientista deva ser munido de grande perspicácia, espírito crítico e outras qualidades diversas, a paciência não é apanágio de todos. Se as cozinhas já dispõem da 'Bimby', os laboratórios também já podem ter moinhos de bolas. Estes "almofarizes sofisticados" existem em diversas versões, sendo os modelo planetário e vibratório os mais usados (Figura 2), e permitem obter o produto desejado em poucos minutos

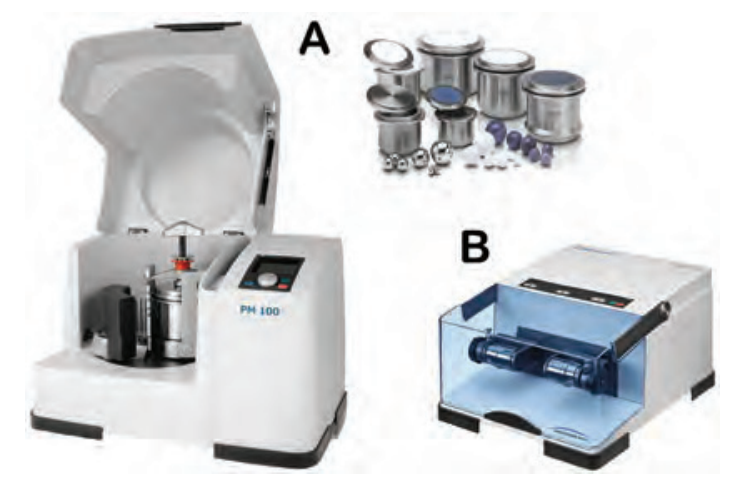

Figura 2 - Moinhos de bolas usados em mecanoquímica. A) modelo planetário e acessórios. B) modelo vibratório. Imagens retiradas do website da empresa alemã Retsch. 
e sem mexer um dedo! ou quase... Da minha experiência pessoal devo confessar que o modelo vibratório, para escalas inferiores a um grama, é muito eficiente e fácil de usar.

O uso destes equipamentos é relativamente recente, contudo existe já alguma literatura que nos poderá auxiliar na escolha das condições mais adequadas à nossa reacção. Não temos que nos preocupar com o solvente ou com a temperatura - as reacções são na maior parte dos casos feitas à temperatura ambiente ou a baixa temperatura por congelamento dos reagentes com azoto líquido, apenas para facilitar a moagem - mas sim com outros factores. O material do reactor e das bolas, o número de bolas por reactor e o seu diâmetro, a frequência de rotação ou vibração e o tempo são parâmetros que determinam o sucesso da reacção e que precisam de ser optimizados.

Mas... como ocorre uma reacção mecanoquímica? O processo é simples e envolve um série de eventos que conduzem à formação do produto final. O esquema 1 ilustra os vários passos envolvidos.

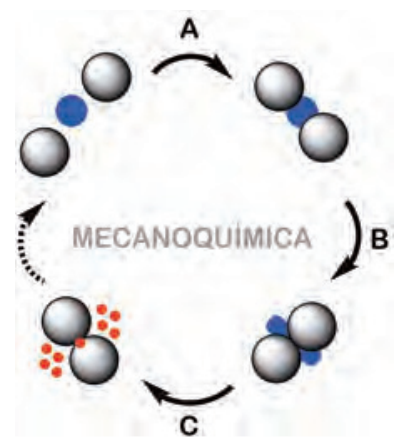

Esquema 1 - Etapas de uma reaç̧ão mecanoquímica: A) deformação elástica, B) deformação plástica e estiramento e C) fractura, amorfização e reacção química.

A revisão da literatura de reacções efectuadas por via mecanoquímica ilustra de forma clara o potencial desta metodologia [5,6]. O interesse despertado pela simplicidade da técnica e o seu perfil "verde” conduziu os químicos, em especial, a revisitar muitas das reacções clássicas da química orgânica. Antes de mostrar alguns exemplos gostaria de sublinhar a importância das condições experimentais numa reacção por via mecanoquímica, com as quais a maioria dos químicos não está ainda familiarizado. A síntese de $1 H$-pirazolonas é um exemplo bastante elucidativo desta abordagem [7]. Neste estudo os autores verificaram que o uso de um moinho de bolas planetário com um reactor de aço $(25 \mathrm{~mL})$ com 5 bolas de aço (diâmetro de $10 \mathrm{~mm}$ ) usando uma frequência de 450 rpm (rotações por minuto) durante $3 \mathrm{~min}$. conduz a rendimentos entre 67 e $84 \%$ (Esquema 2).

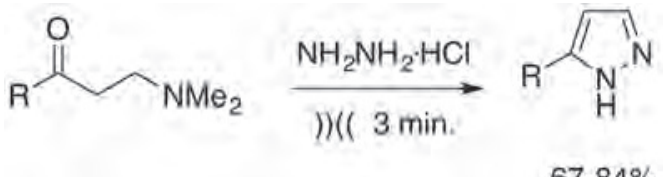

Esquema 2 - Síntese mecanoquímica de $1 H$-pirazolonas.
Pequenas variações nestes parâmetros reduzem significativamente a eficiência da reacção. Contudo de uma forma geral os factores que influenciam o rendimento das reacções mecanoquímicas seguem a ordem: frequência $>$ tempo > tamanho das bolas > número de bolas > material. Para facilitar o isolamento de certos produtos de reacção são adicionados auxiliares de moagem à mistura reacional. Estes auxilares são sólidos inertes, tais como silica gel ou $\mathrm{NaCl}$, que evitam a formação de produtos pastosos ou viscosos que se possam agarrar às paredes do reactor.

Nesta altura o leitor deverá estar já a pensar se poderá realizar as suas reacções por via mecanoquímica. Aquela reacção que teima em não funcionar... ou aquele rendimento que nos estraga a via de síntese, será esta a solução?

No esquema 3 estão representados apenas alguns exemplos [8-15] de reacções clássicas da química orgânica realizadas com sucesso e que poderão servir de inspiração. A mecanoquímica descrita na literatura é já bastante extensa e variada. É interessante verificar que por exemplo no caso das reacções de acoplamento de Heck e Suzuki, catalisadas por paládio, os rendimentos serem superiores aos obtidos por irradiação com micro-ondas. A metodologia também pode ser aplicada em síntese assimétrica [16], sendo portanto de extrema importância para a indústria farmacêutica.

Embora até ao momento nos tenhamos focados essencialmente na síntese de pequenas moléculas, esta metodologia pode ser igualmente usada na construção de sistemas mais complexos (Esquema 4). Alguns exemplos destes sistemas são a funcionalização de materiais [17-19], a síntese de macrociclos [20] e polímeros [21]; com aplicações diversas, da catálise [22] à preparação de baterias [23].

As potencialidades e a versatilidade da mecanoquímica são ilimitadas, com a vantagem de dar uma resposta efectiva à redução de custos de produção e impacto ambiental (menos solventes, menos tempo, menos energia, maior sustentabilidade). O equipamento envolvido é de fácil operação, baixo custo, pode operar em modo contínuo ou em batch e está disponível até à escala do kilograma. É de salientar que os moinhos de bolas são usados desde o período da revolução industrial, quando a invenção da força a vapor permitiu o seu desenvolvimento, tendo sido usados maioritariamente na indústria dos pigmentos.

Face ao exposto a mecanoquímica é sem dúvida um passo em frente na progressiva sustentabilidade da síntese química, à qual não podemos ficar indiferentes. Moer ou não... eis a (nova) questão!

Nota: O símbolo ))(( foi escolhido pelo autor para representar uma reacção mecanoquimica, em analogia com simbologia ))) usada nas reações promovidas por irradiação por micro-ondas. 


\section{Oxidação}<smiles>c1ccc2c(c1)Cc1ccccc1-2</smiles>

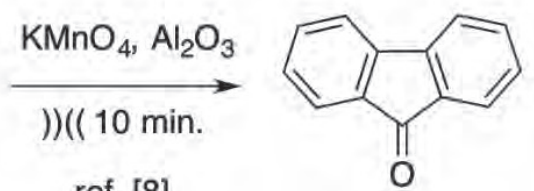
ref. [8]

Condensação [Knoevenagel]<smiles>[R]c1ccc(C=O)cc1</smiles>

1. )) (( $10 \mathrm{~min}$ 2. $\mathrm{NMe}_{3}, 24 \mathrm{~h}$

3. Vácuo, $100^{\circ} \mathrm{C}$ ref. [10]<smiles>N#C/C(=C\c1ccc(P)cc1)C(N)=O</smiles>

$100 \%$

\section{Redução}

$\mathrm{R}^{1} \stackrel{\mathrm{O}}{\mathrm{H}_{R^{2}}}$

$\frac{\text { 1. } \mathrm{NaBH}_{4}}{\stackrel{\text { 2. } \mathrm{H}_{2} \mathrm{O}}{((10-90 \mathrm{~min} \text {. }}}$

${ }_{>99 \%}{\stackrel{\mathrm{OH}}{\mathrm{R}^{2}}}^{\mathrm{OH}}$

ref. [9]

\section{Adição [Diels-Alder]}

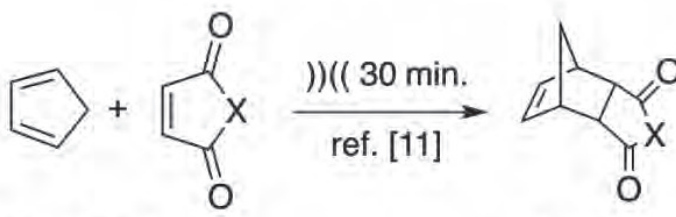

$\mathrm{X}=\mathrm{O}, \mathrm{NR}$

$90-98 \%$

\section{Halogenação}

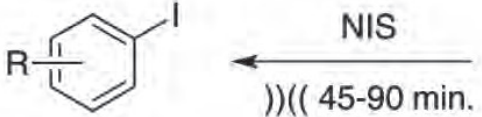

$70-80 \%$

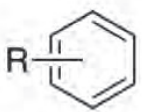

ref. [12]

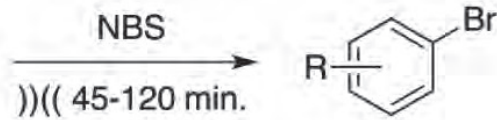

$75-98 \%$

Acoplamento catalisado por paládio [Heck, Suzuki e Sonogashira]<smiles>C=CC(=O)OCC</smiles>
$\mathrm{X}=\mathrm{Br}, \mathrm{I}$<smiles>[X]c1ccccc1CCCC[N+]#[N+]</smiles>

$\mathrm{Pd}(\mathrm{OAc})_{2}, \mathrm{~K}_{2} \mathrm{CO}_{3}$

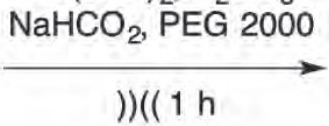

ref. [13]<smiles></smiles>

$29-100 \%$

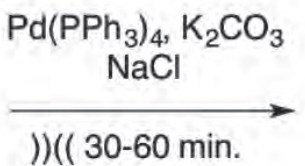

ref. [14]

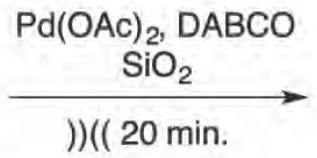

ref. [15]

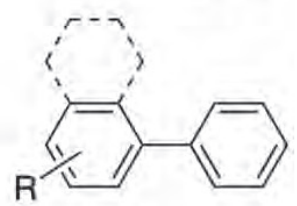

$0-96 \%$<smiles>[R7]C1C=CC(C#C)=CC1</smiles>

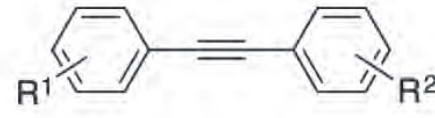

$51-99 \%$ 


\section{Fulerenos}

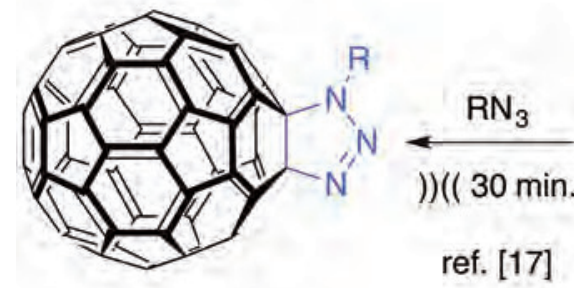

$62-76 \%$

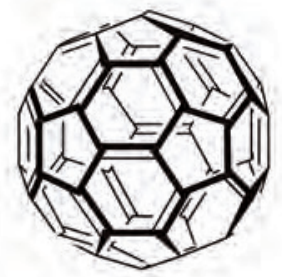

$\mathrm{C}_{60}$

\section{$\underset{\mathrm{Zn}, \mathrm{BrCH}_{2} \mathrm{CO}_{2} \mathrm{Et}}{\stackrel{\mathrm{Zn}}{\longrightarrow}}$}

ref. [18]

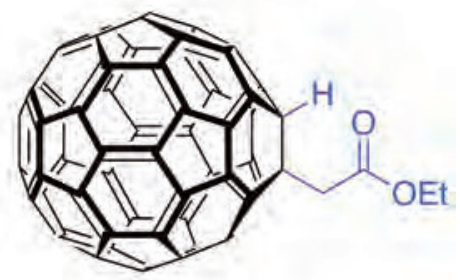

$17 \%$

$\left(62,5 \%\right.$ com base no $\mathrm{C}_{60}$ consumido)

\section{Grafeno}

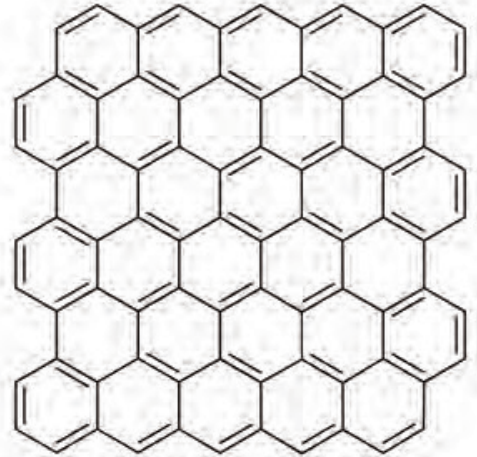

Grafite

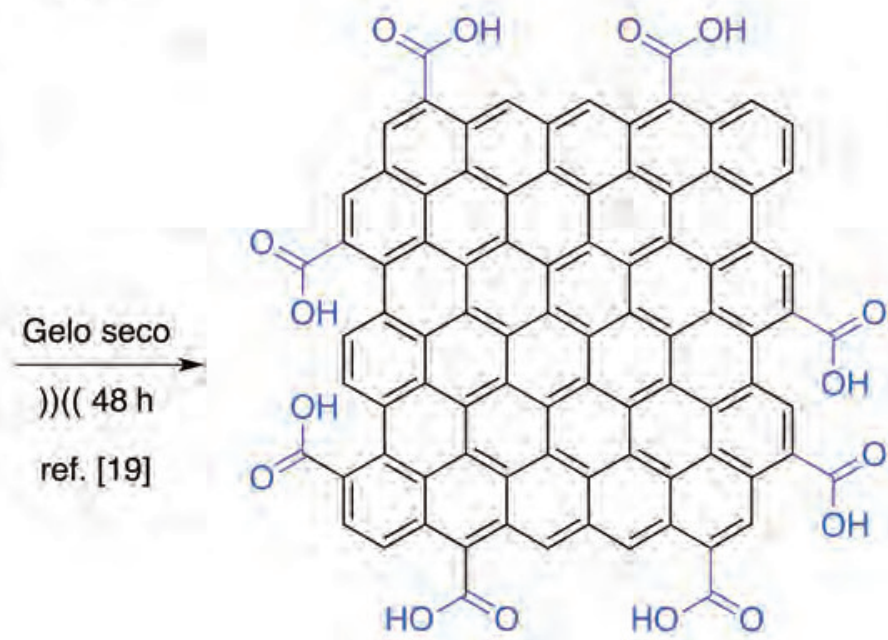

\section{Porfirinas}

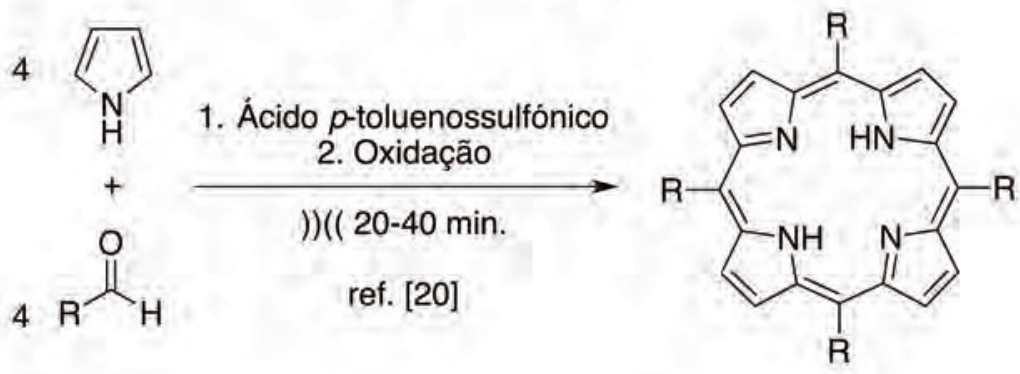

Poli(fenileno vinileno)<smiles>CCCCC(CC)COc1cc(CCl)c(OC)cc1CCl</smiles> 


\section{REFERÊNCIAS}

[1] K. Wright, Paléorient 17 (1991) 19-45

[2] V. André, M.F.M. da Piedade, M.T. Duarte, CrystEngComm 14 (2012) 5005-5014

[3] M.B. Gawande, V.D.B. Bonifácio, R. Luque, P.S. Branco, R.S. Varma, ChemSusChem (2014) 24-44

[4] K. Tanaka, Solvent-free organic synthesis, $2^{\text {nd }}$ completely revised and updated edition, WILEY-VCH, 2008.

[5] S.L. James, C.J. Adams, C. Bolm, D. Braga, P. Collier, T. Friščić, F. Grepioni, K.D.M. Harris, G. Hyett, W. Jones, A. Krebs, J. Mack, L. Maini, A.G. Orpen, I.P. Parkin, W.C. Shearouse, J. W. Steed, D.C. Waddelli, Chem. Soc. Rev. 41 (2012) 413-447

[6] G.-W. Wang, Chem. Soc. Rev. 42 (2013) 7668-7700

[7] G.C. Paveglio, K. Longhi, D.N. Moreira, T.S. München, A.Z. Tier, I.M. Gindri, C.R. Bender, C.P. Frizzo, N. Zanatta, H.G. Bonacorso, M.A.P. Martins, ACS Sustainable Chem. Eng. 2 (2014) 1895-1901

[8] M. Nüchter, B. Ondruschka, R. Trotzki, J. Prakt. Chem. 342 (2000) 720-724

[9] M.R. Naimi-Jamal, J. Mokhtari, M.G. Dekamin, G. Kaupp, Eur. J. Org. Chem. (2009) 3567-3572

[10] G. Kaupp, M.R. Naimi-Jamal, J. Schmeyers, Tetrahedron 59 (2003) 3753-3760

[11] Z. Zhang, Z.-W. Peng, M.-F. Hao, J.-G. Gao, Synlett (2010) 2895-2898
[12] A. Bose, P. Mal, Tetrahedron Lett. 55 (2014) 2154-2156

[13] V. Declerck, E. Colacino, X. Bantreil, J. Martinez, F. Lamaty, Chem. Commun. 48 (2012) 11778-11780

[14] S. F. Nielsen, D. Peters, O. Axelsson, Synth. Commun. 30 (2000) 3501-3509

[15] R. Thorwirth, A. Stolle, B. Ondruschka, Green Chem. 12 (2010) 985-991

[16] M. Jörres, J. L. Aceña, V. A. Soloshonok, C. Bolm, ChemCatChem. 7 (2015) 1265-1269

[17] K. Komatsu, Y. Murata, G.-W. Wang, T. Tanaka, N. Kato and K. Fujiwara, Fullerene Sci. Technol. 7 (1999) 609$-620$

[18] G.-W. Wang, Y. Murata, K. Komatsu and T.S.M. Wan, Chem. Commun. (1996) 2059-2060

[19] I.-Y. Jeon, Y.-R. Shin, G.-J. Sohn, H.-J. Choi, S.-Y. Bae, J. Mahmood, S.-M. Jung, J.-M. Seo, M.-J. Kim, D. W. Chang, L. Dai, J.-B. Baek, PNAS 109 (2012) 5588-5593

[20] H. Shy, P. Mackin, A.S. Orvieto, D. Gharbharan, G.R. Peterson, N. Bampos, T.D. Hamilton, Faraday Discuss. 170 (2014) 59-69

[21] J.B. Ravnsbæk, T.M. Swager, ACS Macro Lett. 3 (2014) 305-309

[22] C. Xu, S. De, A.M. Balu, M. Ojedad, R. Luque, Chem. Commun. 51 (2015) 6698-6713

[23] B. Zhang, R. Dugas, G. Rousse, P. Rozier, A.M. Abakumov, J.-M. Tarascon, Nature Commun. 7 (2015) 10308.

\section{Actualidades Científicas}

\section{MATERIAL PROTEICO COM PROPRIEDADES AUXÉTICAS}

Um novo material proteico revela propriedades invulgares, à luz do senso comum: quando esticado numa direcção, o material torna-se mais fino na direcção perpendicular; quando comprimido numa dimensão, ele reduz-se noutra ao invés da expansão que seria teoricamente observada.

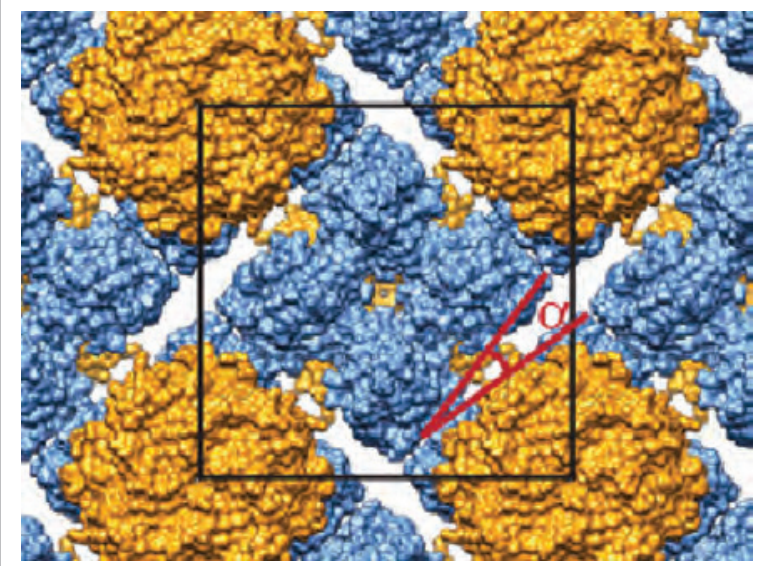

Estas propriedades invulgares são designadas por propriedades auxéticas e resultam do facto do coeficiente de Poisson, que mede a deformação transversal (em relação à direcção longitudinal da aplicação da força) de um material, ter um valor negativo.

Recentemente, um grupo de investigadores da Universidade da Califórnia - San Diego criou um material cristalino bidimensional (2D) obtido através de unidades proteicas ligadas num padrão regular. Para construírem o material recorreram à L-ramnulose 1- fosfato aldolase (RhuA), um homotetramero escolhido pela sua forma quadrangular. O material mostrou possuir um coeficiente de Poisson de -1, o menor valor termodinamicamente possível para um material isotrópico.

(adaptado de Protein crystals stretch knowledge of exotic materials, http://www.rsc.org/chemistryworld/2016/05/auxetic-protein-crystal-stretches-knowledge-exotic-materials e de Y. Suzuki, G. Cardone, D. Restrepo, P.D. Zavattieri, T.S. Baker, F.A. Tezcan, Nature (2016) DOI: 10.1038/ nature17633)

Paulo Mendes (pjgm@uevora.pt) 


\section{Antoine-LAurent LAVOISIER}

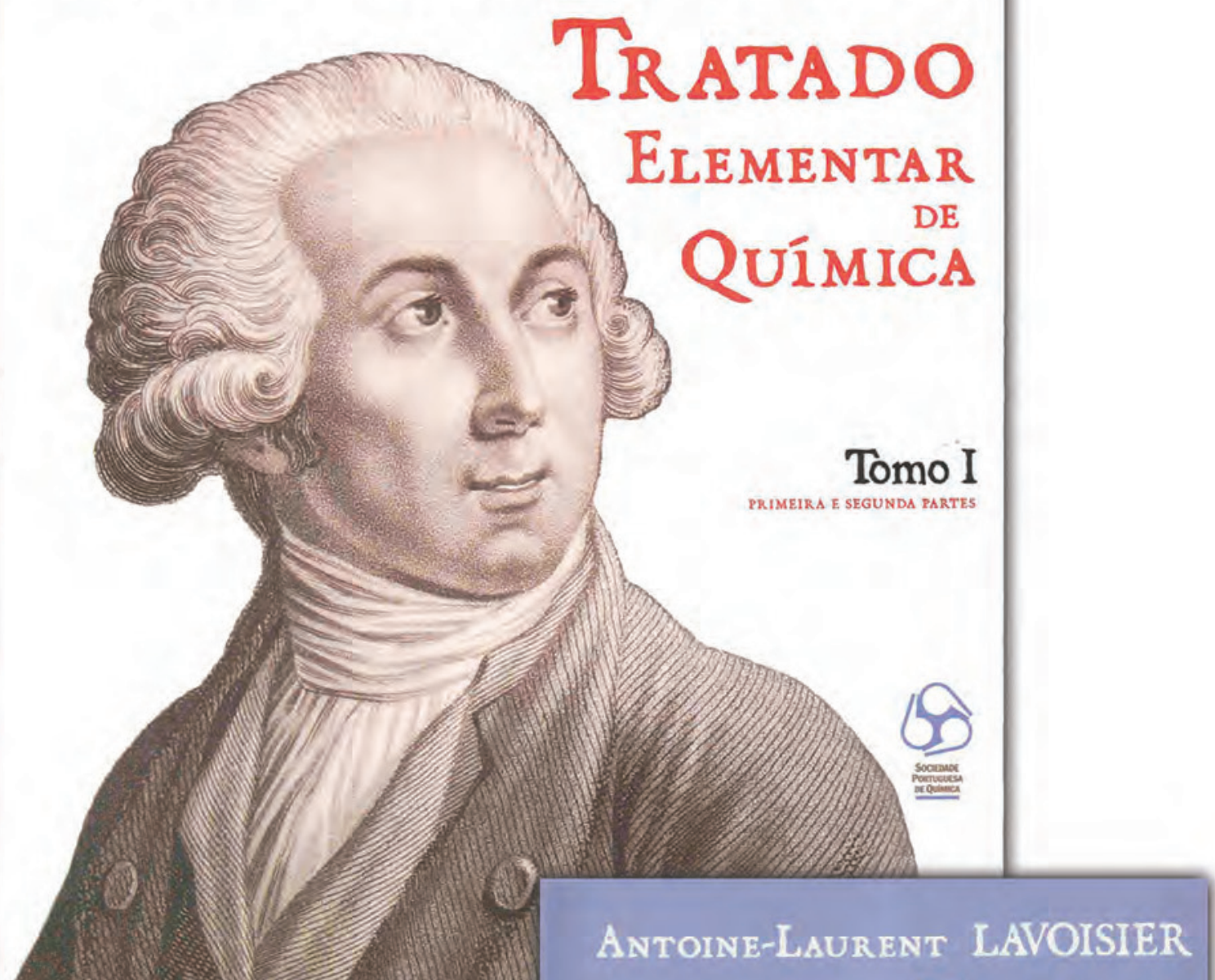

0 "Tratado Elementar de Química» de Antoine-Laurent Lavoisier (1743-1794), publicado em Paris em 1789, é um dos grandes clássicos da Química. Escrito na nova nomenclatura proposta também por Lavoisier, em conjunto com Morveau, Berthollet e Fourcroy, é a primeira obra de química moderna, abandonando-se as inadequadas designações de raízes alquímicas e a desacreditada teoria do flogisto. No tratado, ilustrado pela mulher do autor, Marie-Anne-Pierrette Paulze Lavoisier, formula-se de forma clara a conservação da matéria e define-se elemento químico de forma operacional.

No centenário da fundação da Sociedade Portuguesa de Química, publica-se finalmente uma cuidada tradução portuguesa do «Traité», modernizada e anotada.

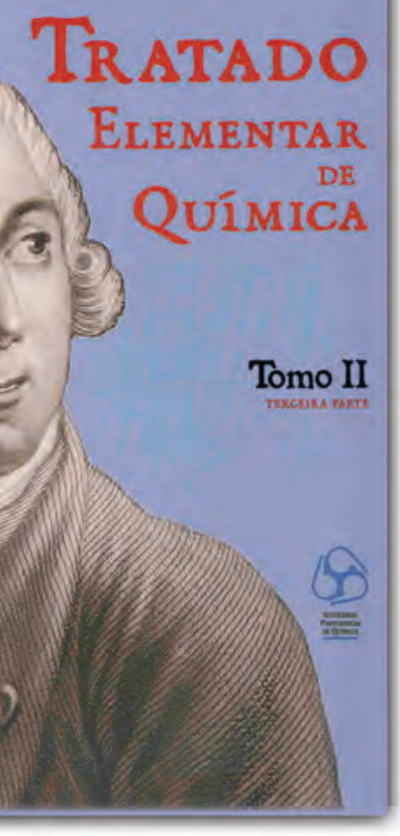

